\title{
ANALYTICAL INVESTIGATION OF CARTONNAGE FRAGMENT FROM LATE PERIOD
}

\author{
Abd El-Tawab, N. ${ }^{1}$, Badr, I. ${ }^{2} \&$ Mahran, A. ${ }^{2}$ \\ 1Ass. Prof., Conservation dept., Faculty of Archaeology, South Valley Univ., Qena, Egypt \\ ${ }^{2}$ Lecture in Institute of tourism, Hotel management and Restoration, Alexandria
}

E-mail:drnabil_bader@yahoo.com

\begin{abstract}
Technical and analytical studies were carried out on a late period cartonnage fragments from unknown mummy at Egyptian museum, which was found at middle Egypt at Asyut. The structure of the object was visually examined and the layer of textiles, plaster, pigments and binder were identified. The fragments was examined using a variety of techniques; Optical light microscopy (OLM), X-Ray fluorescence (XRF), X-Ray diffraction, Fourier transform infrared spectroscopy (FTIR) and Scanning electron microscopy with energy-dispersive analysis of elements (SEM-EDX). Analytical studies indicated that, the ground layer was composed of calcite and traces of quartz. Carbon black was used as black pigment while Hematite as red pigment and Orpiment As2O3 used as yellow pigment, these showing the influence of Roman and Greek pigments on Egyptian art in these later periods. Green colorant was identified as Malachite. Animal glue was used in the four pigments as medium colored.
\end{abstract}

Keywords: Cartonnage, Cairo museum, Ground layer, Pigments, Binder, Linen

\section{Introduction}

Cartonnage is one of the most important archaeological materials that are found on the mummies and including it from there, colors, scenes, texts and the writings of ancient which can be revealed through them for many of the facts, historical information and secrets [1].Cartonnage is a type of cardboard-like material. It was used by the ancient Egyptians in a manner similar to how we would use papier-mâché today. It was constructed from layers of linen which had been moistened and stuck together using a kind of paste and then it was coated with a layer of stucco (lime plaster or gesso). It would then be molded into various shapes and left to dry. When it had dried it could then be painted or gilded [2]. During the Greco-Roman period, papyrus was sometimes used instead of the layer of linen [3]. During the Pharonic times; cartonnage was used to make the inner coffins for mummies. It was molded to the shape of the body, forming a one-piece shell. These coffins were often highly decorated with various geometric designs, an assortment of deities and inscriptions, which included verses from the Book of the Dead [4]. During Ptolemaic times, a new, simpler method of mummy decoration was adopted. Instead of encasing the mummy in a one-piece mummiform shell, it would be covered with four to six 
separate pieces of decorated Cartonnage. These would be attached to the outer mummy wrappings and could easily be mass produced. These separate sections of Cartonnage consisted of a mask covering the head and shoulders, a pectoral, an apron for the legs and a foot casing. Sometimes, two additional pieces were added to cover the ribcage and stomach [1]. To evaluate the type and the properties of the materials as well as the problems at the diagnosis step, is necessary to prepare the restoration and conservation projects. Especially of the original materials as plaster, pigments, binding medium and others used at decorated and pictorial archaeological objects as cartonnage, will help to choose and to produce the repair materials. Having this information, the restoration materials will be chemically, physically compatible with the original ones [5]. This work aimed to analyzed some small fragments $(3.7 \times 2.5 \mathrm{~cm})$ of Egyptian cartonnage taken from unknown mummy from the late period, dated to 688-332 BC., found by prisoners digging earth to fill birkeh at Asyut (Lykopolis, (Lykopolis, Zawty), fig. (1). It was one of the collections of Egyptian Museum, taking ID Number 13.3.15.1(d). Analytical investigations were done and proved that, these cartonnage appears similar in style to other examples dated to the late Greco Roman (Pre-Ptolemaic).
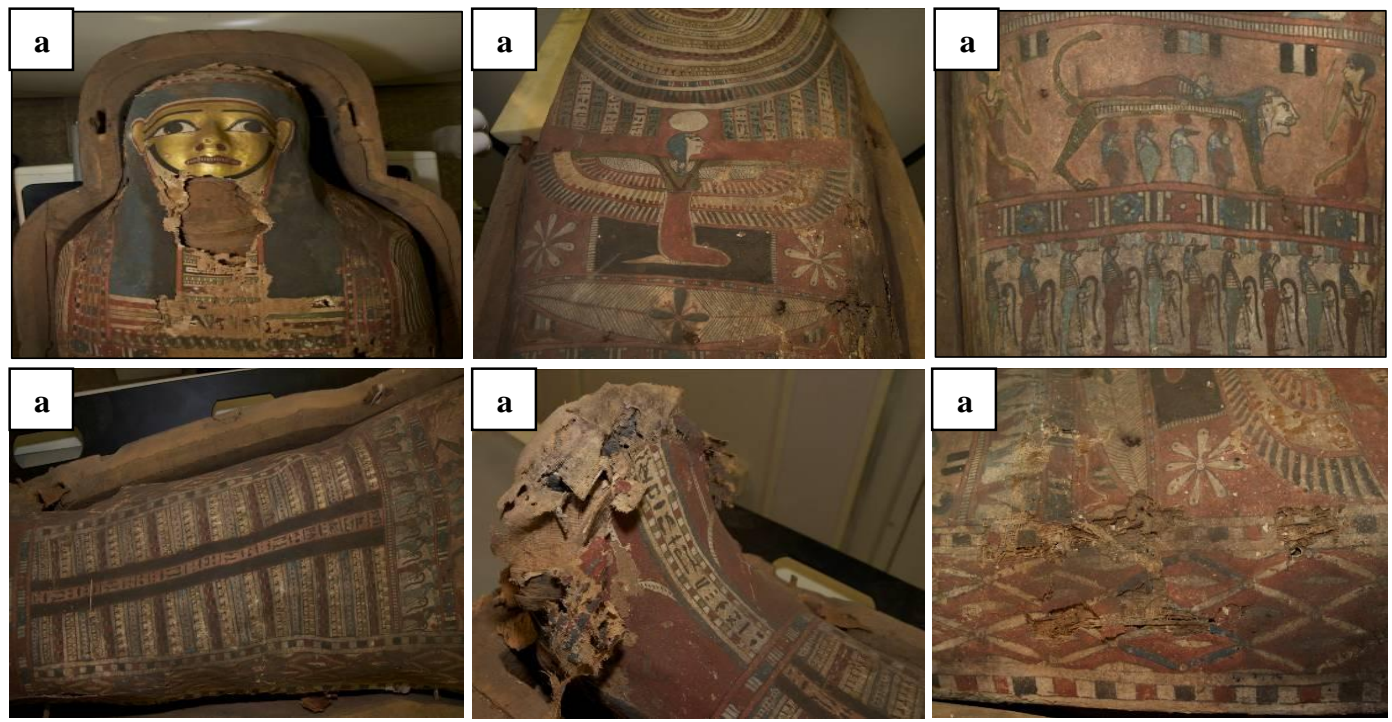

Figure (1) $\underline{\mathbf{a}}, \underline{\mathbf{b}}, \underline{\mathbf{c}}$ Greek Roman mummy coated by cartonnage, $\underline{\mathbf{d}}, \underline{\mathbf{e}}, \underline{\mathbf{f}}$ Bad condition of cartonnage.

\section{Materials and Methods}

The scientific examination was intended to elucidate the nature of the ground layer, pigments binding media and support employed in cartonnage as well as to establish the state of conservation of the cartonnage. Samples were observed by an Olympus BX40 optical stereomicroscope, and recorded with digital camera under 40-60X magnification. Samples were investigated by microscopy (SEM JEOL JSM 6400) coupled with energy dispersive microanalysis (EDX). The sample sputter coated with gold. Selected samples were examined using $\mathrm{X}$-ray fluorescence (XRF) to obtain the total element content qualitatively and quantitatively. XRF measurements were performed in situ nondestructive analysis. XRF spectrometer for elemental analysis (JSX3222), equipped with end window type $\mathrm{X}$-ray tube, tube voltage 5 to $50 \mathrm{Kv}$ (in $1 \mathrm{Kv}$ steps), tube current 0.01 to $1.0 \mathrm{~mA}$, using $\mathrm{Rh}$ anode as target, window $\mathrm{Be}$, $127 \mu \mathrm{m}$ thick. X-ray fluorescence was detected by an $\mathrm{X}$ Flash silicon drift 
detector with high speed electronics with an energy resolution $149 \mathrm{eV}$ at $\mathrm{Fe} \mathrm{K} \alpha$ spectral line (5.9 keV, 4000cps). The Samples were also analyzed by X-ray diffraction (XRD) using PW1840 diffractrometer with $\mathrm{Cu} \mathrm{K} \alpha$ radiation (40 $\mathrm{kV}, 25 \mathrm{~mA}$ ), rotating sample holder and proportional detector. Measurements were carried out in the range 5.005: 59.995 with a step of 0.010 . The ICDD data bank of standard X-ray powder spectra was used for phase identification. Binding medium was studied by Fourier

\section{Results}

The first step in undertaking conservation is to examine an object closely, both with the naked eye and under magnification. Careful examination will often reveal a great deal of detail about the materials and methods used in

\subsection{Bulk elemental analysis by XRF}

\subsubsection{Plaster layer}

Their elemental composition analysis carried by XRF revealed that they were consisted of high amounts of calcium $(\mathrm{Ca})$, and quartz with low 3.1.2. Pigments:

The XRF microanalysis obtained on the pigment samples showed that the chromatic palette used for decorating the transform infrared spectroscopy (FTIR). The samples were analyzed as $\mathrm{KBr}$ pellets by JASCO FT\IR-460 plus. Powdered samples pressed into potassium bromide $(\mathrm{KBr})$ pellets and the powder mixture was then crushed in a mechanical die press to form a translucent pellet. $\mathrm{KBr}$ pellets of powdered samples were examined between 4000 and $400 \mathrm{~cm}^{-1}$ at a resolution of $4 \mathrm{~cm}^{-1}$. Spectra were acquired between $1000-4000 \mathrm{~cm}^{-1}$.

the manufacture of the object. It may also reveal how the object was used in antiquity. The technology of the materials used in the fabrication of ancient Egyptian cartonnage is still not fully investigated [6].

amounts of magnesium $(\mathrm{Mg})$, sulphure $(\mathrm{S})$, potassium $(\mathrm{K})$, Aluminum $(\mathrm{Al})$, chloride $(\mathrm{Cl})$ and Sodium (Na), fig. (3-a).

cartonnage is based mainly on earth pigments, the investigations results are shown in tab. (1) \& fig s. (3-b, c, d, e).

Table (1) XRF results of cartonage pigments.

\begin{tabular}{|c|c|c|c|c|}
\hline \multirow{2}{*}{ Element } & Red pigment & Yellow pigment & Green pigment & Black pigment \\
\hline & $\%$ & $\%$ & $\%$ & $\%$ \\
\hline $\mathrm{Na}$ & 3.16 & -- & -- & 3.14 \\
\hline $\mathrm{Mg}$ & 1.27 & -- & -- & -- \\
\hline $\mathrm{Al}$ & 2.25 & 1.50 & 2.50 & 1.60 \\
\hline $\mathrm{Si}$ & 7.62 & 10.55 & 17.75 & 8.89 \\
\hline $\mathrm{S}$ & 3.20 & 7.81 & 5.22 & 1.92 \\
\hline $\mathrm{Cl}$ & 3.25 & 1.04 & -- & 2.47 \\
\hline K & 2.04 & 1.67 & 3.14 & 1.87 \\
\hline $\mathrm{Ca}$ & 60.97 & 71.19 & 43.95 & 77.89 \\
\hline $\mathrm{Ti}$ & -- & 0.42 & -- & 0.42 \\
\hline $\mathrm{Fe}$ & 15.58 & 1.32 & 1.72 & -- \\
\hline As & 0.57 & 4.46 & 0.81 & -- \\
\hline $\mathrm{Pb}$ & -- & -- & 0.45 & -- \\
\hline $\mathrm{Cu}$ & -- & -- & 24.01 & -- \\
\hline $\mathrm{Mn}$ & -- & -- & -- & 0.52 \\
\hline
\end{tabular}



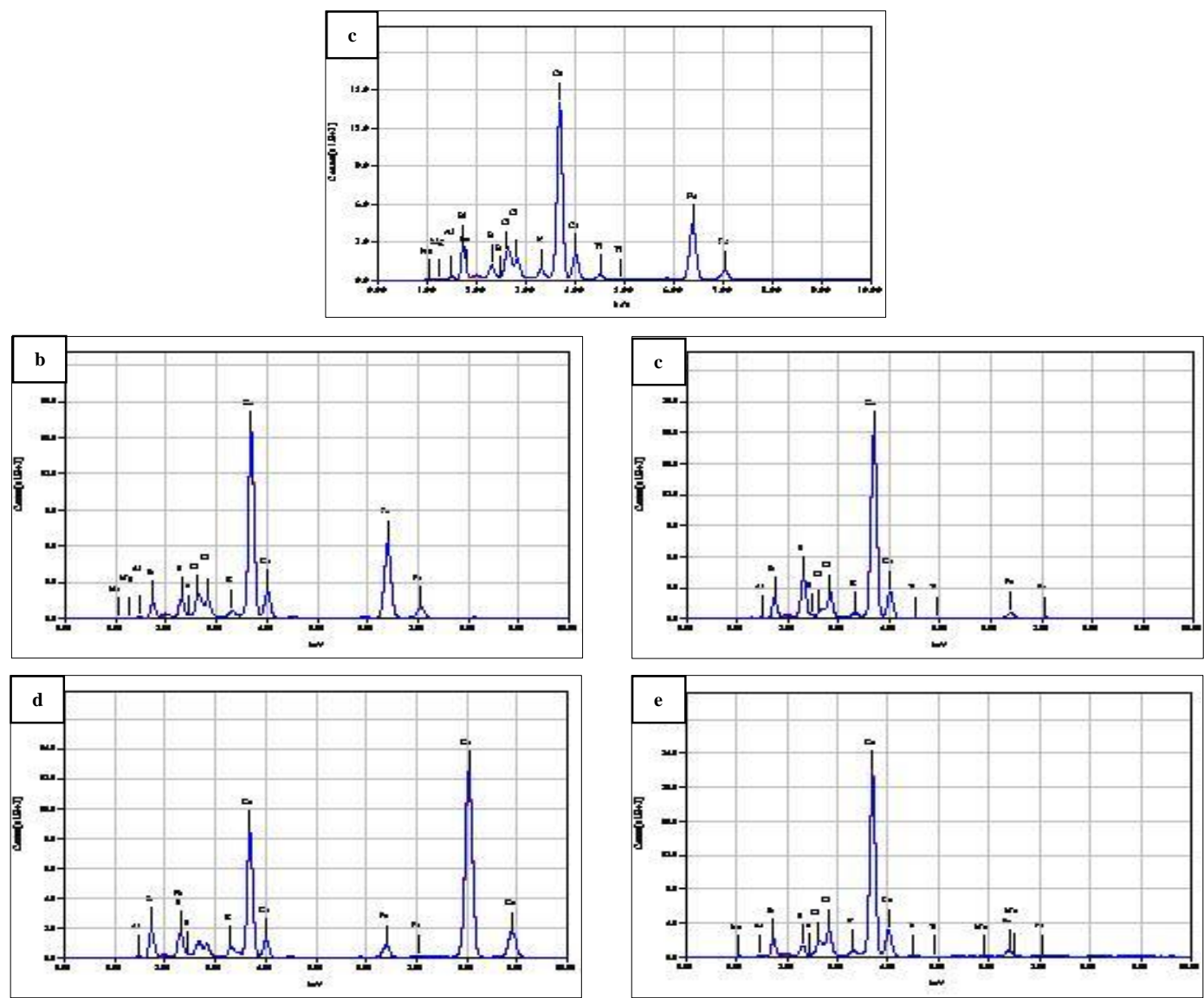

Figure 3 (a-e) XRF patterns of the cartonnage, $\underline{\mathbf{a}}$ plaster sample, $\underline{\mathbf{b}}$ red pigment, $\underline{\mathbf{c}}$ yellow pigment, $\underline{\mathbf{d}}$ green pigment, $\underline{\mathbf{e}}$ black pigment.

\subsection{Mineralogical analysis by XRD}

\subsubsection{Plaster layer}

Mineralogical composition of plaster layers on the obverse and reverse of the cartonnage were determined by $\mathrm{X}$ -

\subsubsection{Pigments}

XRD identified the red pigment as Hematite $\mathrm{Fe}_{2} \mathrm{O}_{3}$, yellow pigment attributed to Orpiment $\mathrm{As}_{2} \mathrm{~S}_{3}$ and traces of Iron oxide, green pigment attributed to the Malachite $\mathrm{CuCO}_{3} \mathrm{Cu}(\mathrm{OH})_{2}$.

ray diffraction (XRD). The results showed that plaster layer is a lime plaster, fig. (4-a).

Furthermore, XRD analysis proved that, the sample contains crystalline phase related to carbon black, all results are shown in tab. (2) and fig. (4-b, c, d, e).

Table (2) XRD results of cartonage pigments.

\begin{tabular}{|c|c|}
\hline $\begin{array}{l}\text { Kind } \\
\text { samples }\end{array}$ & Compounds \\
\hline Plaster layer & Calcite $\mathrm{CaCO}_{3}$, Quartz $\mathrm{SiO}_{2}$ and Kaolinite $\mathrm{Al}_{2} \mathrm{Si}_{2} \mathrm{O}_{5}(\mathrm{OH})_{4}$ \\
\hline Red pigment & Calcite $\mathrm{CaCO}_{3}$, , Quartz $\mathrm{SiO}_{2}$, Hematite $\mathrm{Fe}_{2} \mathrm{O}_{3}$ \\
\hline Yellow pigment & $\begin{array}{l}\text { Calcite } \mathrm{CaCO}_{3} \text {, Quartz } \mathrm{SiO}_{2} \text {, Orpiment } \mathrm{As}_{2} \mathrm{~S}_{3} \text {, Iron oxide } \mathrm{Fe}_{2} \mathrm{O}_{3} \text { and } \\
\text { Kaolinite } \mathrm{Al}_{2} \mathrm{Si}_{2} \mathrm{O}_{5}(\mathrm{OH})_{4}\end{array}$ \\
\hline Green pigment & $\begin{array}{l}\text { Calcite } \mathrm{CaCO}_{3} \text {, Quartz, } \mathrm{SiO}_{2}, \text { Malachite } \mathrm{Cu} \mathrm{CO}_{3} \mathrm{Cu}(\mathrm{OH})_{2} \text {, Gypsum } \\
\text { CaSO4.2 } \mathrm{H}_{2} \mathrm{O} \text { and Kaolinite } \mathrm{Al}_{2} \mathrm{Si}_{2} \mathrm{O}_{5}(\mathrm{OH})_{4}\end{array}$ \\
\hline Black pigment & Calcite $\mathrm{CaCO}_{3}$, Graphite Charcoal $\mathrm{C}$ and Kaolinite $\mathrm{Al}_{2} \mathrm{Si}_{2} \mathrm{O}_{5}(\mathrm{OH})_{4}$ \\
\hline
\end{tabular}



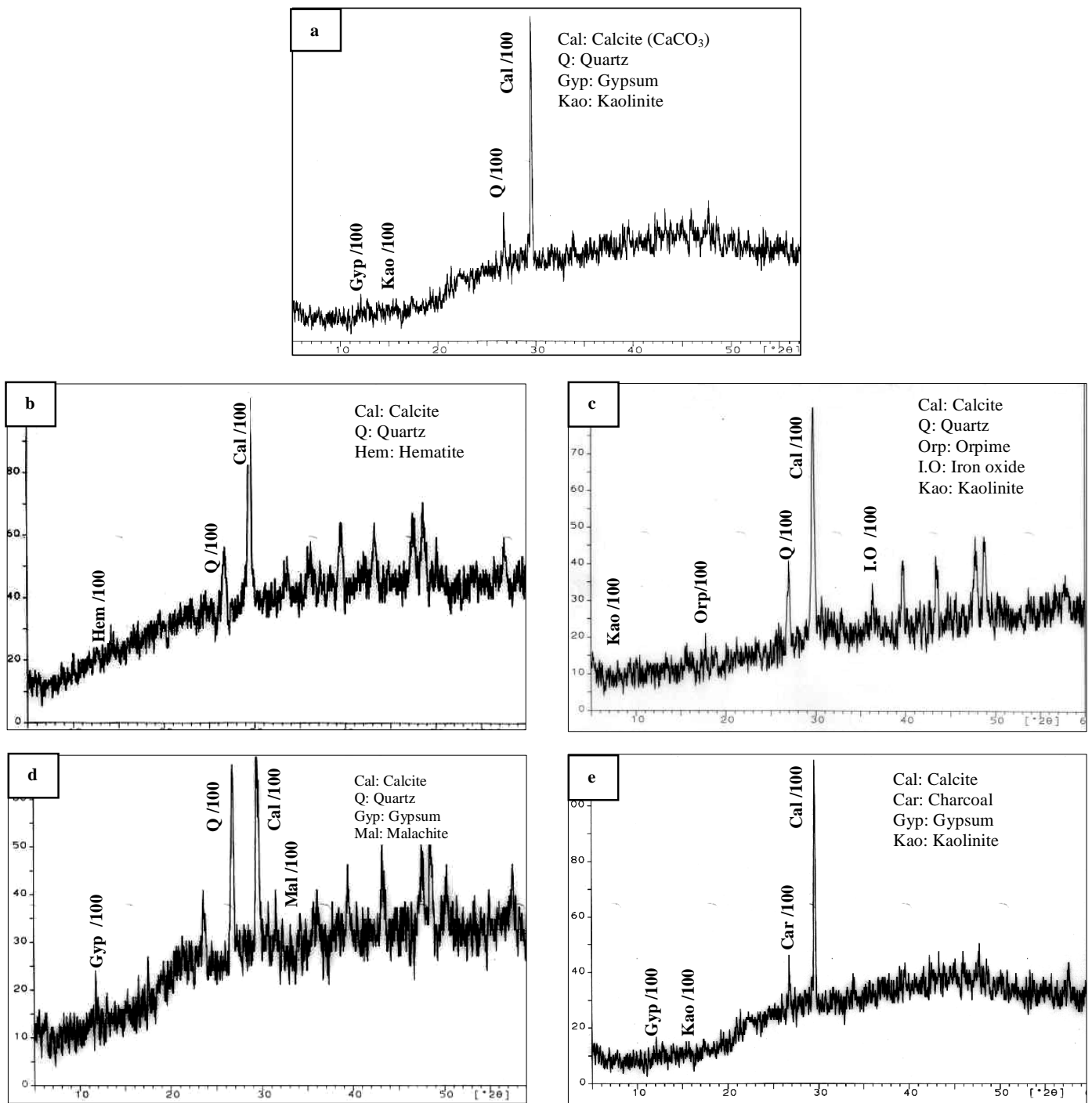

Figure (4) XRD patterns of the cartonnage pigments $\underline{\mathbf{a}}$ plaster sample, $\underline{\mathbf{b}}$ red pigment, $\underline{\mathbf{c}}$ yellow pigment, $\underline{\text { d }}$ green pigment, $\underline{\mathbf{e}}$ black pigment.

\subsection{Optical investigation by (LOM)}

Through investigation by LOM, it could be observed that the samples have thick layers of colors, and some of their parts were separated from painting

layer, all investigations are shown in fig. (5- a, b, c, d). Furthermore, the support is composed from linen fibers, fig. (5- a, b, c).
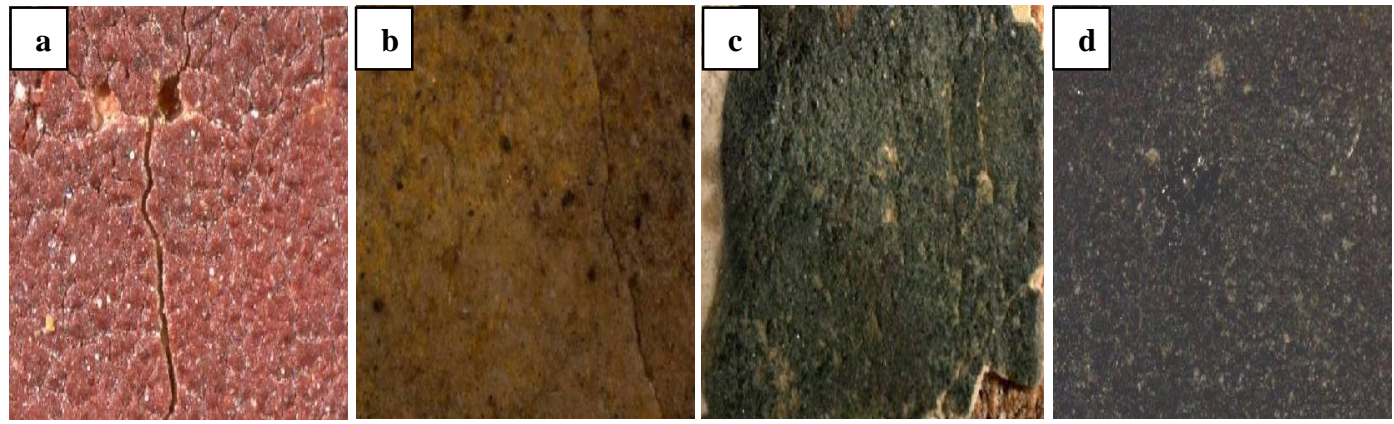

Figure (4) LOM photomicrograph of the paint layer of cartonnage $\underline{\mathbf{a}}$ red pigment $\underline{\mathbf{b}}$ yellow pigment $\underline{\mathbf{c}}$ Green pigment $\underline{\mathbf{d}}$ black pigment. 

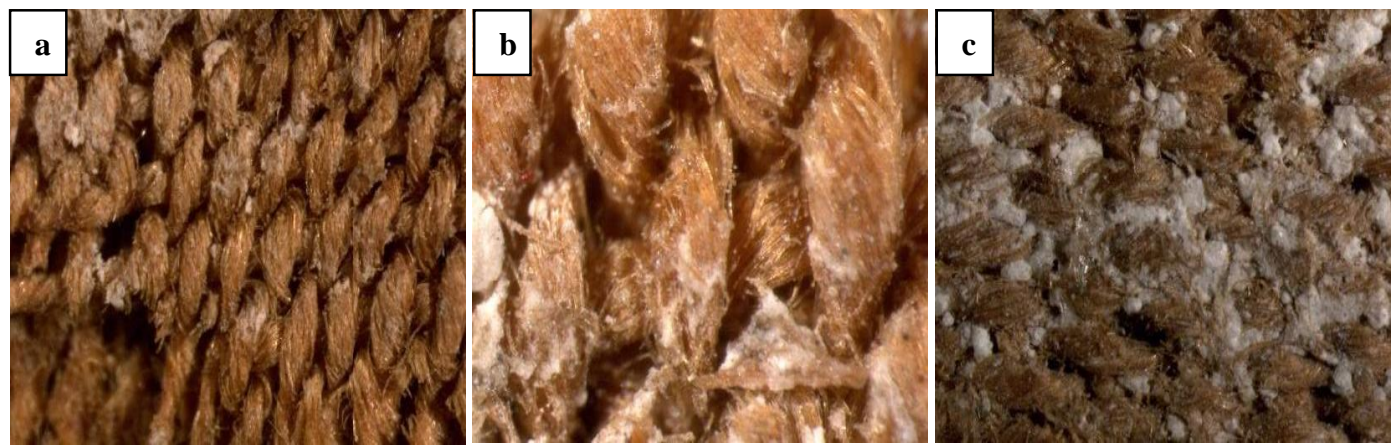

Figure (5) Morphology of linen fibers under LOM.

\subsection{Morphological investigation by (SEM)}

Layer and canvas support and pigmented materials were examined by Scanning Electron Microscope; the results are shown in fig. (6-a, b) \& fig. (7-a, b, c).
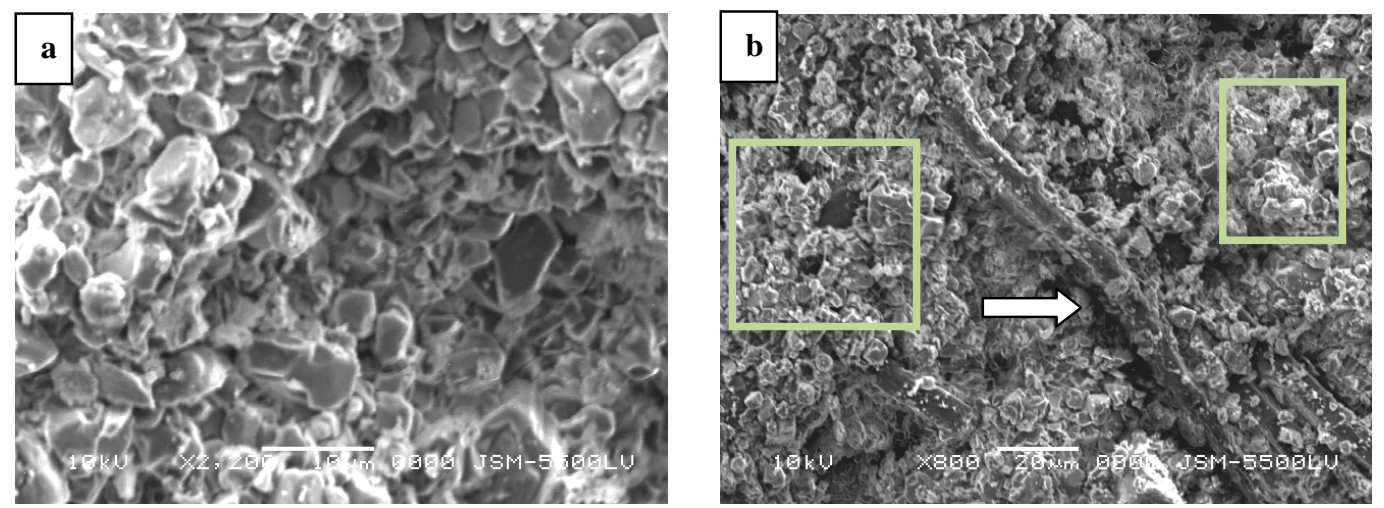

Figure (6) SEM micrograph of lime plaster shows $\underline{\mathbf{a}}$ the fine grains of calcite $\underline{\mathbf{b}}$ plaster affected by salts and fungi hyphae.
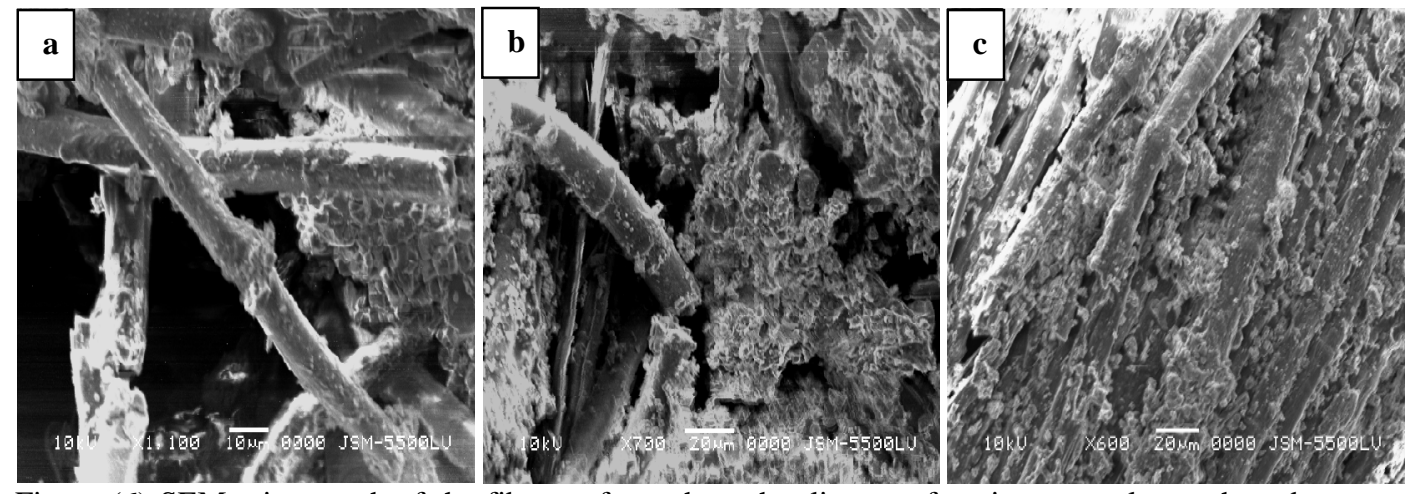

Figure (6) SEM micrograph of the fiber surface, show that linen surface is extremely roughened, very damage and broken with transverse cracking and longitudinal splitting characterized by small scratches, large slits and holes.

\subsection{FTIR results}

Small sample from the red pigment was taken for detailed examination using FTIR analysis, to identify the possible binding medium that could have been employed on the cartonnage. The results of FTIR analysis were compared with reference spectra with well-known organic adhesives. The sample spectrum was compared with spectra of Arabic gum, animal glue and yellow and yolk egg as shown in tab. (3). FTIR analysis shows that the residue of the bonding material is animal glue, fig. (7). 
Table (3) the relation between function group of red pigment and function group of glue.

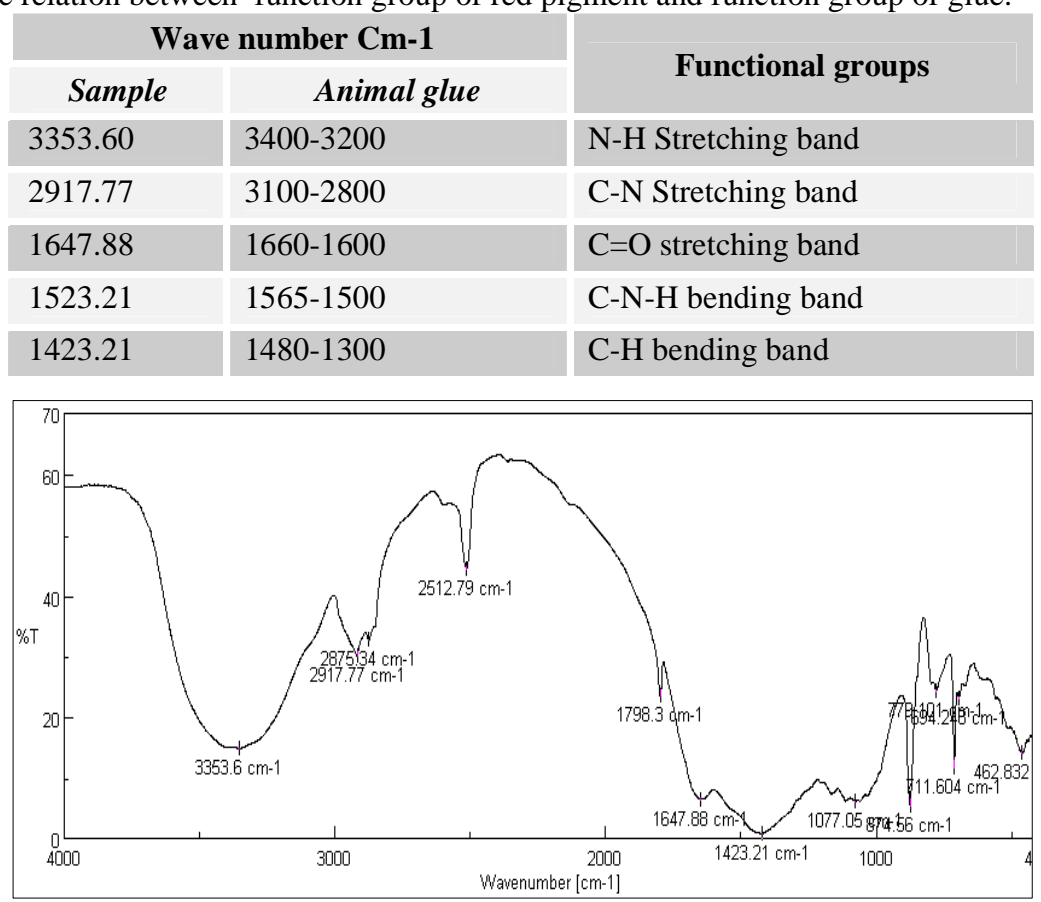

Figure (7) FTIR spectra of paint layers samples of cartonnage.

\section{Discussion}

The application of some analytical methods such as LOM, SEM-EDS, XRF and FT-IR was an

\subsection{Paint layer}

Considering the XRF results, it can be concluded that plaster layer of the Cartonnage was prepared with lime, Quartz and gypsum. The presence of chloride and sodium reflect the halite salts is probably due to contact with the reserve mummy from the Natron which be used for the embalming process, which could easily have soaked through outer wrappings onto the inner surface of the cartonnage [7]. The presence of aluminum $(\mathrm{Al})$ and potassium $(\mathrm{K})$ are from dust particles. The presence of $\mathrm{Mg}$ Owed to limestone which had been used in makes lime. XRD patterns of the

\subsection{Pigments}

The results showed that the Egyptian artist used earth pigments for decorating the cartonnage. Red pigments: XRF microanalysis identifies calcium, iron, silicon, and aluminum as the main elements. This composition agrees with the XRD pattern of the red attempt to answer questions concerning materials and painting technique.

plasters layers indicated that they were mainly consists of calcite $\left(\mathrm{CaCO}_{3}\right)$-based plaster, with peaks matching Gypsum $\left(\mathrm{CaSO}_{4} \cdot 2 \mathrm{H}_{2} \mathrm{O}\right)$ and quartz $(\mathrm{SiO} 2)$ together with some suggestion of the presence of Kaolinite $\left(\mathrm{Al}_{4} \quad\left(\mathrm{Si}_{4} \mathrm{O}_{10}\right)\right.$ $\left.(\mathrm{OH})_{8}\right)$ [8]. Calcite is originated from lime and quartz from aggregates. Under the SEM microscope, the calcite is present in very fine grains. Also the SEM micrograph reveals Gypsum and halite crystals. In addition to, the SEM micrograph indicated fungal hypha inner the plaster structure.

earth, where we have identified a mixture of compounds formed by hematite $\left(\mathrm{Fe}_{2} \mathrm{O}_{3}\right)$ responsible for the red color, calcite, and quartz. The intense peaks of calcite in the XRD spectrum can be due to the presence of the compounds from the white layer, smaller peaks for 
aluminum perhaps attributed to ochre. Red hematite is abundant in weathered rocks (ochres, gossans and soils) and imparts a strong color. Aluminum may substitute into hematite up to $15 \mathrm{wt} \%$ [9]. The microscopic examination of the samples from the iron based red pigments shows coarse morphology of the surface, homogeneous distribution of the pigment, some places shows fading of the color with some micro-cracks distributed on the entire pigment surface. Yellow pigment: The yellow sample of the cartonnage was analyzed by X-ray fluorescence and the spectra showed prominent peaks for arsenic (As $4.46 \%$ ). The only yellow arseniccontaining pigments are orpiment. XRD results improved that yellow pigment attributed to Orpiment $\mathrm{As}_{2} \mathrm{~S}_{3}$ and/or iron, suggesting the use of mixed with yellow ochre and showed the presence of Calcite $\mathrm{CaCO}_{3}$ and Quartz $\mathrm{SiO}_{2}$ which owed to ground layer. The microscopic examination showed the rough morphology of the yellow surface. The pigment surface is inhomogeneous in thickness, most probably due to inadequate preparation of the paint layers. There were also black spots in the coarse grains due to the additives that were mixed with it. The yellow colors appeared to have faded to a very weak yellow in many areas such fading is characteristic of the pigment orpiment, $\mathrm{As}_{2} \mathrm{~S}$ [7]. Orpiment is a yellow to greenish yellow sulfide of arsenic $\left(\mathrm{As}_{2} \mathrm{~S}_{3}\right)$, containing $60 \%$ arsenic [10]. Early known uses of orpiment as a pigment occur in Middle and New Kingdom Egypt (sixteenth to eleventh centuries BC) as painted decoration on wooden coffins and stelae and as a cosmetic [11]. Because of its bright color,

\subsection{The binder}

Chemical composition of the binder was determined by FT-IR analyses. The FT-IR spectrum of the binding media was similar with the ones of made with animal glue. Animal glues were derived from many sources: the pigment was popular for use on mediaeval manuscripts and it has been identified from the Book of Kells [12]. It was undoubtedly the most prized yellow for our artists, even when mixed with blues to obtain greens [13]. Green pigment: $\mathrm{X}$-ray fluorescence of this sample revealed peaks for copper (24.1\%), with some additional peaks for iron $(\mathrm{Fe} 1.72 \%)$ and Lead $(\mathrm{Pb} 0.75 \%)$ calcium and Silicone from the ground was also detected. XRD analysis of the green pigment improved that green pigment attributed to the Malachite $\mathrm{Cu}$ $\mathrm{CO} 3 \mathrm{Cu}(\mathrm{OH}) 2$, presence of Calcite Quartz and gypsum are owed to ground layer. The microscopic examination of the samples from green pigment showed inhomogeneous composition and revealed the presence of amorphous non-crystalline particles. Malachite is a green basic copper carbonate mineral with composition $\mathrm{Cu} 2 \mathrm{CO} 3(\mathrm{OH}) 2$. Its name is derived from the Greek word, meaning 'mallow', and referring to its leaf green color. For use as a pigment, malachite was prepared by crushing, grinding, washing and levigating [10]. Black pigment: XRF analysis indicates, $\mathrm{Ca}$ and $\mathrm{Si}$ are the dominant elements. The sample contains small amount of Mn. But XRD analysis proved that, the sample contains crystalline phase related to carbon black. Calcite $\mathrm{CaCO}_{3}$ and Quartz $\mathrm{SiO}_{2}$ were recorded, which related to ground layer. The examination of the black color by LOM showed the compact surface of the sample, the color layer is very thin. The opaque pigment consisted of small agglomerations of fine particles.

fish, calf skins and even cheese. The most widely acknowledged best glue for this purpose was been calf-skin glue or rabbit-skin glue. Rabbit skin glue can be obtained in many fine art stores today. 


\subsection{The support}

The surface of the canvas fiber below the radish and the yellowish colors were investigated by Light Optical microscope (LOM) for identifying the fibers. However the Optical microscope is a tool which is commonly used to identify the fibers [14]. Fiber identification proved that the fibers are from linen. The results of the light optical Microscope show that there is progressive damage in textile. SEM photomicrograph of examined samples show that linen is the fibers and show also, that linen surface is extremely roughened, very damage and broken with transverse cracking and longitudinal splitting characterized by small scratches, large slits and holes. Moreover the results show that, these textile are broken and had lost most of their strength and the other mechanical properties. This is directly proportional to the damage on the surface morphology of fibers [13]. The SEM and LOM investigation improved that the cartonnage in this mummy suffer serious deterioration aspects as result of the physiochemical and microbiological effects of the deterioration factors and the obtained results will be used in the conservation and preservation interventions regarding these cartonnage.

\section{Conclusion}

Technical and analytical studies were carried out on painted cartonnage fragments taken from unknown mummy that belonged to the Late Greek Roman period, dated to 688-332 BC from the collection of Egyptian museum. The component of cartonnage making, ground layers, pigments, color medium and layers of textiles were identified by using different analytical methods as XRD, XRF, LOM, SEM and FTIR. The analytical methods results showed that, the ground layer is composed of calcite $\mathrm{CaCO}_{3}$ as a major with small amounts of quartz (SiO2). Read pigment that used is Hematite $\mathrm{Fe}_{2} \mathrm{O}_{3}$. Yellow pigment is Orpiment $\mathrm{As}_{2} \mathrm{~S}_{3}$; Green pigment is Malachite $\mathrm{Cu} \mathrm{CO}_{3} \mathrm{Cu}(\mathrm{OH})_{2}$. The black pigment was identified as carbon black and $X R F$ detected presence of Manganese (Mn). FTIR results indicated that, the binding medium could be identified as animal glue. The examination of the canvas fiber below the radish and the yellowish colors by LOM and SEM proved that the cartonnage was made from layers of linen and it was in a very bad condition.

\section{References}

[1] Teeter, E., (1994). Egyptian art, ancient art at the art institute of Chicago, Museum Studies, Vol. 20 (1), pp. 1 96.

[2] Bagnall, R. \& Reading P., (1995). Writing ancient history, Routledge Press, NY

[3] Adams, C., (1996). The manufacture of ancient Egyptian cartonnage cases, The Smithsonian Journal of History, Vol. 1, pp. 55- 66

[4] Picton, J., Quirke, S., Roberts, P., (2007). Living Images. Egyptian funerary portraits in the Petrie museum. Walnut creek, California

[5] Ahmet, G., (2011). Characterization of the mortars and plasters of Ayasofya of Enez (AINOS), $5^{\text {th }}$ int. cong. on safeguard of cultural heritage in the Mediterranean basin, Istanbul, pp. 134146
[6] Afifi, H., (2011). Analytical investigation of pigments, ground layer and media of cartonnage fragments from Greek roman period, $M A A$, Vol. 11, (2), pp. 91-98

[7] David A. Scott, M., Narayan, K., Keeney, D. \& Dodd, L., (2003). An Egyptian cartonnage of the GrecoRoman period examination and discoveries, Studies in Conservation, Vol. 48 (1), pp. 41-56

[8] El-Gohary, M., 2012. The environmental factors affecting the archaeological buildings in Egypt-part 1, in Interdisciplinary research on the works of art, Justyna Olszewska-Świetlik, Joanna M. Arszyńska, Bożena Szmelter-Fausek (eds.) Nicolaus Copernicus University, Toruń, Poland, pp. 151-165 
[9] Grave, E., De Bowen, L. Awarasiriwardena, D. Vandenberghe, (1988). Fe Mössbauer effect study of highly substituted aluminum hematites: determination of the magnetic hyperfine field distributions, J. of Magnetism \& Magnetic Materials, Vol. 72, pp. 129-140

[10] Eastaugh, N., Walsh, V., Chaplin, T. \& Siddall, R., (2004). The pigment compendium: A dictionary of historical pigments, Elsevier.

[11] Colinart, S., (2001). Analysis of inorganic yellow color in ancient Egyptian painting, in Davies, W. (ed.) Color and painting in ancient
Egypt British Museum Press, London, pp. 1-4.

[12] Mehan, B. (1994). The Book of Kells, Thames \& Hudson, Dublin.

[13] Seldes, A., Burucúa, J., Siracusano, G., Marta, S. \& Gonzalo E., (2002) Green, yellow, and red pigments in South American painting, 1610-1780, JAIC, Vol. 41 (3), pp. 225-242.

[14] Abdel-Kareem, O., El-Nagar, K., (2005). Non-destructive methods to investigate the deterioration extent of Coptic Egyptian textiles, journal of Textile and Apparel, Technology and Management, Vol. 4 (4), pp.1-15 